\title{
Toll-Like Receptor 4 Polymorphisms (896A/G and I 196C/T) as an Indicator of COVID-19 Severity in a Convenience Sample of Egyptian Patients
}

\author{
Sara I Taha $\mathbb{D}^{\text {I }}$ \\ Aalaa K Shata ${ }^{2}$ \\ Shereen A Baioumy $\mathbb{D D}^{3}$ \\ Shaimaa H Fouad (iD ${ }^{4}$ \\ Sherif G Anis ${ }^{5}$ \\ Isis M Mossad ${ }^{6}$ \\ Nouran M Moustafa ${ }^{7,8}$ \\ Dina M Abdou ${ }^{9}$ \\ Mariam K Youssef' \\ 'Department of Clinical Pathology, \\ Faculty of Medicine, Ain Shams \\ University, Cairo, Egypt; ${ }^{2}$ Department of \\ Pulmonary Medicine, Faculty of Medicine, \\ Ain Shams University, Cairo, Egypt; \\ ${ }^{3}$ Department of Microbiology and \\ Immunology, Faculty of Medicine, Zagazig \\ University, Zagazig, Egypt; ${ }^{4}$ Department \\ of Internal Medicine/Allergy and Clinical \\ Immunology, Faculty of Medicine, Ain \\ Shams University, Cairo, Egypt; \\ ${ }^{5}$ Department of Anesthesia and Intensive \\ Care, Faculty of Medicine, Ain Shams \\ University, Cairo, Egypt; ${ }^{6}$ Department of \\ Community, Environmental and \\ Occupational Medicine, Faculty of \\ Medicine Ain Shams University, Cairo, \\ Egypt; ${ }^{7}$ Department of Basic Medical \\ Science, Faculty of Medicine, Dar Al \\ Uloom University, Riyadh, Saudi Arabia; \\ ${ }^{8}$ Department of Microbiology and \\ Immunology, Faculty of Medicine, Ain \\ Shams University, Cairo, Egypt; \\ 'Department of Internal Medicine/ \\ Hematology, Faculty of Medicine, Ain \\ Shams University, Cairo, Egypt
}

Correspondence: Sara I Taha Department of Clinical Pathology, Faculty of Medicine, Ain Shams University,

Abassia, Cairo, Egypt

Tel +20 II 25360009

$\mathrm{Fax}+20224346308$

Email dr_sara_ib@med.asu.edu.eg
Background: The clinical spectrum of COVID-19 is extremely variable. Thus, it is likely that the heterogeneity in the genetic make-up of the host may contribute to disease severity. Toll-like receptor (TLR)-4 plays a vital role in the innate immune response to SARS-CoV-2 infection. The susceptibility of humans to severe COVID-19 concerning TLR-4 single nucleotide polymorphisms (SNPs) has not been well examined.

Objective: The goal of this research was to investigate the association between TLR-4 (Asp299Gly and Thr399Ile) SNPs and COVID-19 severity and progression as well as the cytokine storm in Egyptian patients.

Methods: We genotyped 300 adult COVID-19 Egyptian patients for TLR-4 (Asp299Gly and Thr399Ile) SNPs using PCR-restriction fragment length polymorphism (PCR-RFLP). We also measured interleukin (IL)-6 levels by enzyme-linked immunosorbent assay (ELISA) as an indicator of the cytokine storm.

Results: The minor 299Gly (G) and 399Ile (T) alleles were associated with a significant (P< $0.001)$ positive risk of severe COVID-19 ( $\mathrm{OR}=3.14 ; 95 \% \mathrm{CI}=2.02-4.88$ and $\mathrm{OR}=2.75$; $95 \% \mathrm{CI}=1.66-4.57)$, their frequency in the severe group were $71.8 \%(84 / 150)$ and $70.7 \%$ (58/150), respectively. We detected significant differences between TLR-4 (Asp299Gly, Thr399Ile) genotypes with regard to serum levels of IL-6. Levels of IL-6 increased significantly with the presence of the mutant 299Gly (G) and 399Ile (T) alleles to reach the highest levels in the Gly299Gly (GG) and the Ile399Ile (TT) genotypes (170 pg/mL (145208.25) and $112 \mathrm{pg} / \mathrm{mL}$ (24-284.75), respectively).

Conclusion: The TLR-4 (Asp299Gly and Thr399Ile) minor alleles 299Gly (G) and 399Ile (T) are associated with COVID-19 severity, mortality, and the cytokine storm.

Keywords: COVID-19, Egypt, mortality, polymorphism, severity, Toll-like receptor

\section{Introduction}

Coronavirus disease 2019 (COVID-19) is a respiratory illness caused by severe acute respiratory syndrome coronavirus-2 (SARS-CoV-2). ${ }^{1}$ Even though most patients infected by SARS-CoV-2 are mild cases that can recover spontaneously with appropriate symptomatic treatment, some patients deteriorate rapidly, suffering from hyper-inflammation and cytokine storm, with an increased rate of hospitalization, intensive care admission, and high fatality. ${ }^{2}$ Although there are known risk factors associated with severe diseases such as old age, high body mass index, diabetes mellitus, cardiovascular diseases, chronic chest diseases, and malignancies, ${ }^{3,4}$ disease progression can rapidly occur in some patients, even in 
the absence of obvious risk factors. Thus, it is likely that other factors, such as the heterogeneity of the genetic makeup and the different immune responses of the host, rather than virus alone, may contribute to disease severity.

The innate immune system, the initial line of defense, is in charge of identifying structurally conserved patterns of organisms called pathogen-associated molecular patterns (PAMPs), as well as mounting an early proinflammatory response. ${ }^{5}$ Toll-like receptor 4 (TLR-4) is a critical pattern recognition receptor (PRR) that recognizes multiple PAMPs, from bacteria, mainly lipopolysaccharides (LPS), viruses, and other pathogens. ${ }^{6}$ TLR-4 also identifies certain damage-associated molecular patterns (DAMPs) generated by dead or lytic cells after host tissue injury or viral infection. ${ }^{5}$

Several studies conducted during the COVID-19 pandemic have found that dysregulated TLR-4 signaling may contribute to the initial failure of viral clearance and the development of COVID-19 severe clinical symptoms, namely adult respiratory distress syndrome (ARDS) and lethal respiratory failure. ${ }^{5-9}$

Considering the importance of TLR-4 in initiating innate immunity against SARS-CoV-2, it is supposed that genetic heterogeneity in the TLR-4 gene might explain, at least in part, the broad spectrum of COVID-19 manifestations. Therefore, in this study, we assessed two common TLR-4 single nucleotide polymorphisms (SNPs), Asp299Gly and Thr399Ile, in Egyptian patients with COVID-19 and evaluated their frequency concerning disease severity, progression, and cytokine storm.

\section{Methodology}

\section{Ethical Approval and Consent to Participate}

The current study protocol was approved by the Research Ethics Committee (REC) of Ain Shams University Faculty of Medicine (FWA 00017585). We explained procedures to all participants and obtained their written informed consent before participation in the study. This study adheres to the Declaration of Helsinki.

\section{Sample Size Calculation}

We calculated sample size using STATA program version $17 \mathrm{~B}$ setting the power at $80 \%$ and $\alpha$ error at 0.05 . Suppose the expected odds ratio in the diseased group is 0.3 and the proportion of exposure in the control group is 0.09 . In that case, the ratio of cases-to-controls is 0.21 according to data revealed by Al-Qahtani et al, then 98 cases were needed in each group.

\section{Study Settings and Subjects}

In this cross-sectional study, we selected 150 severe and 150 non-severe COVID-19 adult patients. COVID-19 infection was confirmed by positive real-time reverse transcription-polymerase-chain reaction (RT-PCR) for respiratory swabs. Based on the World Health Organization (WHO) interim guidance, patients were diagnosed and categorized according to their disease severity. ${ }^{10}$ The severe group $(n=150)$ included patients with one or more of the following: respiratory distress, respiratory failure with mechanical ventilation, shock, organ failure syndrome, or ICU admission.

The non-severe group $(\mathrm{n}=150)$ included patients with mild to moderate disease who did not match severe disease criteria, nonetheless, they had a positive nucleic acid test. We tracked each patient's outcome (hospital discharge or death). All participants were subjected to a thorough clinical and chest CT examination at the time of hospital admission.

\section{COVID-19 Reporting and Data System (CO-RADS)}

The CO-RADS score was assigned based on clinical data, laboratory test results, and chest $\mathrm{CT}$ records of patients. A CO-RADS of 0 indicates no infection; CO-RADS of 1 indicates a highly unlikely suspicion of infection with normal chest CT or non-infectious disease findings; a CORADS of 2 indicates low suspicion with chest CT findings of other infections; a CO-RADS of 3 indicates indeterminate COVID-19 suspicion with chest CT abnormalities indicating infection but not sure of COVID-19; a CORADS of 4 indicates high suspicion of infection with suspicious CT findings but not typical as multifocal consolidations, unilateral ground glass, or confluent; a CORADS of 5 indicates high suspicion with typical chest CT findings, whereas CO-RADS of 6 reflects positive RT-PCR SARS-CoV2 infection. ${ }^{11}$

\section{Chest Computed Tomography Severity Scoring (CT-SS)}

The involvement of each lung lobe was visually assessed and rated from 0 to 5 (degree of involvement: $0-5 \%, 5-$ $25 \%, 26-49 \%, 50-75 \%$, and $>75 \%$ ). The individual lobar grades were summed to get the final score (range 025). ${ }^{12,13}$ 


\section{Routine Laboratory Investigations}

From each participant on their admission, $4 \mathrm{~mL}$ of blood was collected via venipuncture under strict aseptic conditions and divided into two vacutainer tubes: 1) an EDTA-containing tube that was stored at $-80^{\circ} \mathrm{C}$ until genotyping of TLR-4 by PCR restriction fragment length polymorphism (PCR-RFLP) , and 2) a plain tube with no additives from which serum was collected after separation by centrifugation at $3500 \times \mathrm{g}$ for 15 minutes. The separated sera were stored at $-80^{\circ} \mathrm{C}$ until IL-6 analysis by enzyme-linked immunosorbent assay (ELISA).

\section{Interleukin-6 Serum Level Measurement}

Serum levels IL-6 were assessed using human ELISA kits supplied by CUSABIO Technology LLC, Houston, TX 77054, United States (Catalog Number: CSB-E04638h) following the manufacturer's instructions, with a measuring range of $7.8 \mathrm{pg} / \mathrm{mL}-500 \mathrm{pg} / \mathrm{mL}$.

\section{Molecular Analysis of TLR-4 SNPs}

Two TLR-4 Exon SNPs rs4986790 (896A/G, Asp299Gly) and rs4986791 (1196C/T, Thr399Ile) were analyzed using the PCR-RFLP technique. Human DNA amplification from EDTA whole blood, without prior nucleic acid extraction, was performed using the Phusion ${ }^{\mathrm{TM}}$ Blood Direct PCR kit (Thermo Scientific ${ }^{\mathrm{TM}}$, USA, Cat. no.: MAN0012900) and primers for the human TLR-4 gene ${ }^{14}$ (Table 1).

According to manufacturer's instructions, the reaction mixture contained:

- $10 \mu \mathrm{L}$ of $2 \times$ Phusion Blood Direct PCR Master Mix. - $1 \mu \mathrm{L}$ of whole blood.

- $0.5 \mu \mathrm{M}$ of each primer.

- $0.6 \mu \mathrm{L}$ of $50 \mathrm{mM} \mathrm{MgCl} 2$ in a $20 \mu \mathrm{L}$-final volume by RNase-Free Water.

The cycling conditions were as follows: initial denaturation at $98^{\circ} \mathrm{C}$ for $5 \mathrm{~min}$, followed by 40 cycles of denaturation at $98^{\circ} \mathrm{C}$ for $1 \mathrm{~s}$, annealing at $62^{\circ} \mathrm{C}$ (for Asp299Gly) or $60^{\circ} \mathrm{C}$ (for Thr399Ile) for $30 \mathrm{~s}$, and extension at $72{ }^{\circ} \mathrm{C}$ for $30 \mathrm{~s}$, and final extension at $72{ }^{\circ} \mathrm{C}$ for $5 \mathrm{~min}$ and cooling to $4{ }^{\circ} \mathrm{C}$. Subsequently, the 188bp (of Asp299Gly) and 124bp (of Thr399Ile) PCR products were treated with $\mathrm{Nco} 1$ and Hinfl restriction enzymes (Thermo Scientific ${ }^{\mathrm{TM}}$, USA) overnight at $37^{\circ} \mathrm{C}$. The digested products were separated by electrophoresis in a $2.5 \%$ agarose gel and detected by ethidium bromide using an Ultra-Violet Transilluminator (Syngene, Frederick, Maryland, USA). Lengths of Asp299Gly restriction fragments were 188bp in

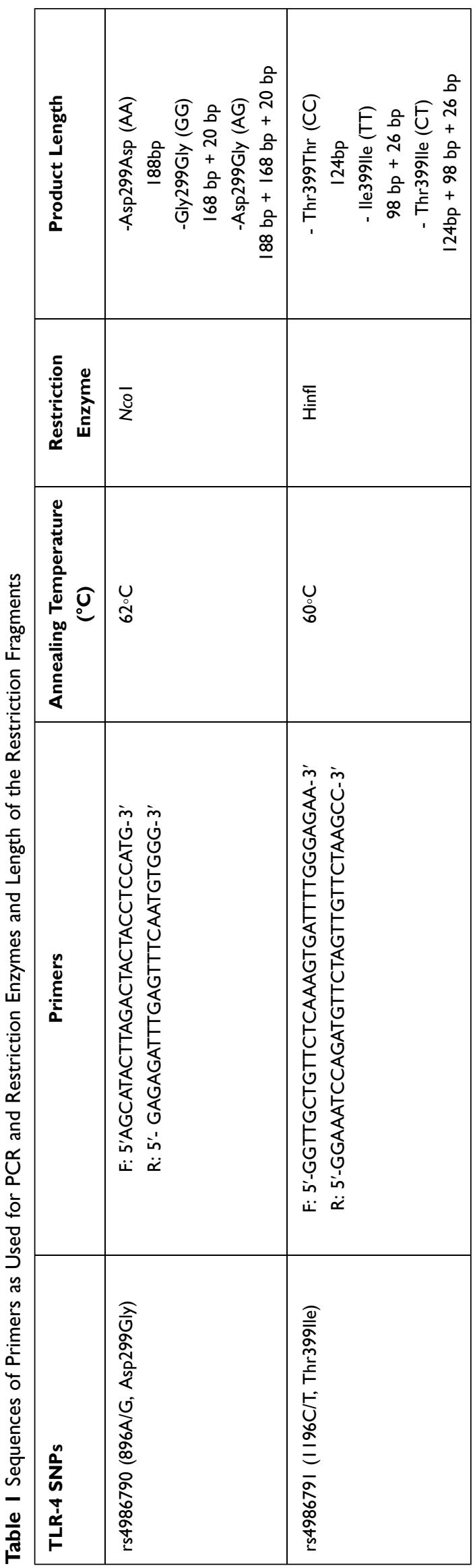




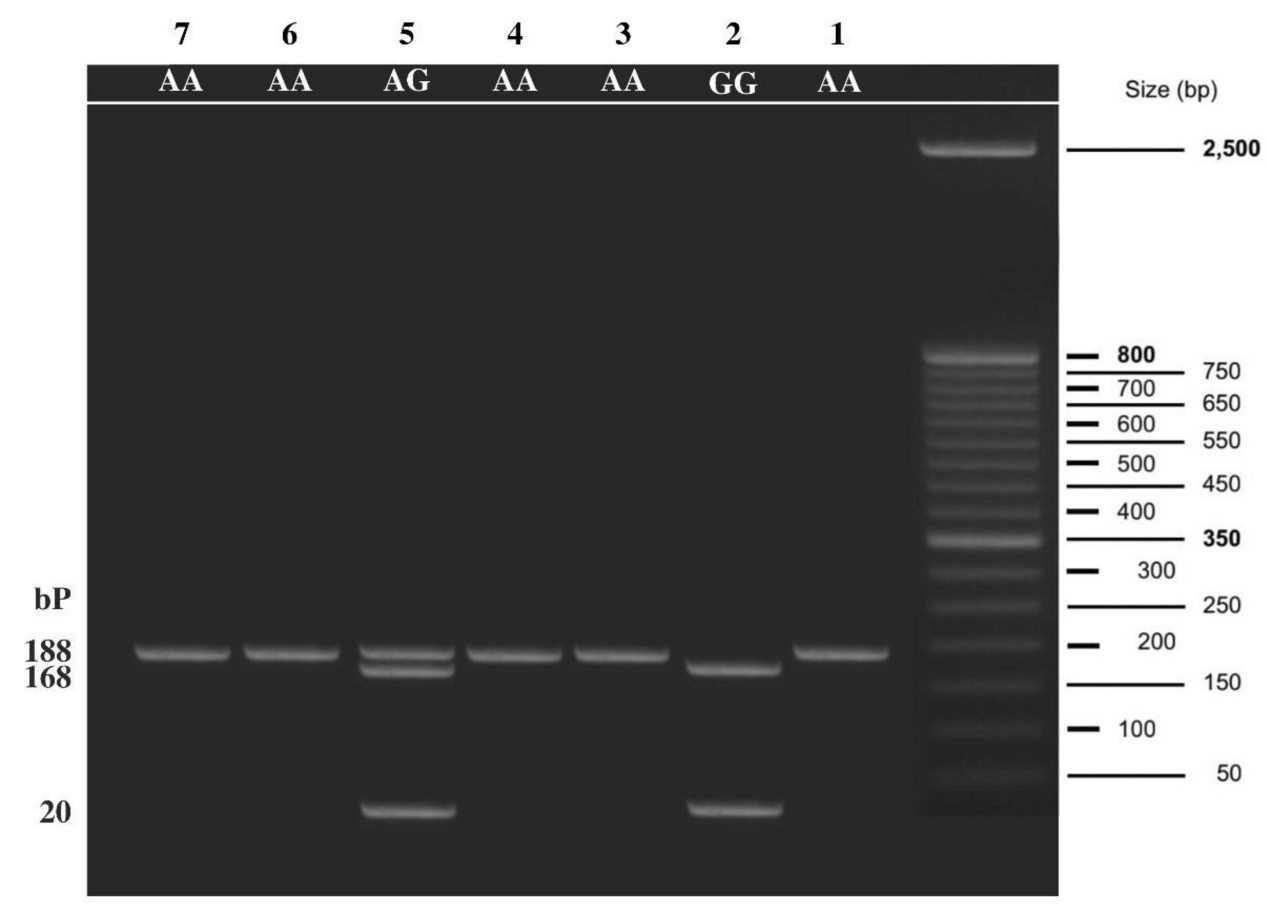

Figure I Agarose gel electrophoresis showing TLR-4 (Asp299Gly) genotyping by PCR -RFLP. Lane I: wild Asp299Asp (AA) genotype at I88 bp (unrestricted); Lane 2: mutant Gly299Gly (GG) genotype at 168 and 20 bp; Lane 5: mutant Asp299Gly (AG) genotype at 188, 168 and 20 bp.

the wild Asp299Asp (AA) genotype, 168 bp +20 bp in the mutant Gly299Gly (GG) genotype, and 188 bp +168 bp +20 bp in the heterozygous mutant Asp299Gly (AG) genotype (Figure 1) while in Thr399Ile restriction fragment lengths were 124bp in the wild Thr399Thr (CC) genotype, 98 bp + $26 \mathrm{bp}$ in the mutant Ile399Ile (TT) genotype, and 124bp +98 $\mathrm{bp}+26 \mathrm{bp}$ in the heterozygous mutant Thr399Ile (CT) genotype (Table 1 and Figure 2). ${ }^{15}$

\section{Statistical Analysis}

We used IBM SPSS Statistics (V. 26.0, IBM Corp., 2019) to analyze the data. The median, percentiles, numbers, and percentages were used to represent the data. With respect to the comparisons, the Chi-square, Wilcoxon Rank Sum, and Kruskall-Wallis tests were utilized. Fisher's exact test was used to analyze the associations of TLR4 SNPs with COVID-19 clinical characteristic severity and in-hospital mortality, as well as odds ratios (OR) and 95\% confidence intervals $(\mathrm{CI})$ were used to interpret the results. At $<0.05$, the probability of error is significant.

\section{Results}

\section{Characteristics of the Study Subjects}

In this study we selected 150 severe and 150 non-severe COVID-19 adult patients. Patients in the severe group were significantly older $(\mathrm{P}<0.001)$. The male-to-female ratio did not differ significantly between the two groups $(\mathrm{P}=0.288)$. The most common related co-morbidities were diabetes and hypertension. Eighty percent (120/150) of the severe group had a severe CT score, compared to only $12 \%$ (18/150) of the non-severe group. There was no significant difference in ICU admission rates between the study patients $(\mathrm{P}=0.533)$. The severe patients' median (IQR) hospital stay was significantly longer than nonsevere patients (19 days (14-22) vs 8 days (5-14); $\mathrm{P}<$ $0.001)$. Severe patients had a substantially higher inhospital death rate than non-severe patients $(25.3 \%$ (38/ $150)$ vs $6.7 \%(10 / 150) ; \mathrm{P}<0.001)$ and showed the highest serum levels of IL-6 (54 pg/mL (30-88) vs 17 pg/mL (1123.5); $\mathrm{P}<0.001)$. The baseline features of the included patients are shown in Table 2 .

\section{TLR-4 SNPs and Risk of Severe COVID-19}

Table 3 shows the correlations between TLR-4 Asp299Gly and Thr399Ile SNPs (genotypes, alleles and haplotypes) and the risk of severe COVID-19. The wild Asp299Asp (AA) and Thr399Thr (CC) genotypes were the most common genotypes among the study groups and were associated with a significant negative risk of severe COVID-19 


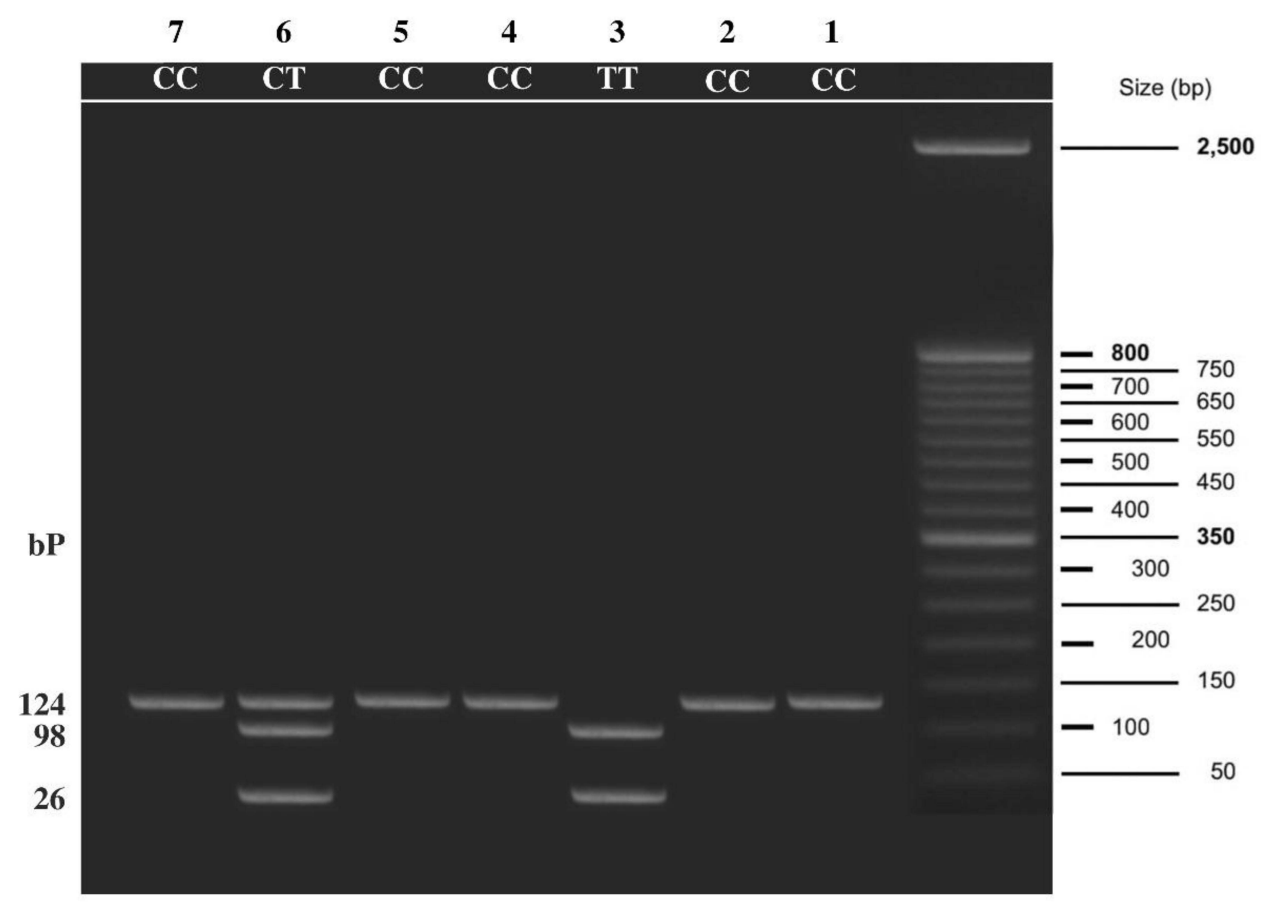

Figure 2 Agarose gel electrophoresis showing TLR-4 (Thr399|le) genotyping by PCR -RFLP. Lane I: wild Thr399Thr (CC) genotype at I24 bp (unrestricted); Lane 3: mutant lle399lle (TT) genotype at 98 and 26 bp; Lane 6: mutant Thr399lle (CT) genotype at I24, 98 and 26 bp.

(Asp299Asp (AA): OR 0.28; 95\% CI 0.17-0.47; P < 0.001 and Thr399Thr (CC): OR 0.27; 95\% CI 0.15-0.49; $\mathrm{P}<$ 0.001). The homozygous mutant Gly299Gly (GG) genotype was detected in $6.7 \%(10 / 150)$ of the severe patients but not in any non-severe patients. On the contrary, the Ile399Ile (TT) genotype was found in $4.0 \%(6 / 150)$ of the non-severe patients and $5.3 \%(8 / 150)$ of the severe patients, but it did not represent a significant risk for severe COVID-19 (OR 0.73; 95\% CI 0.25-2.18; P = 0.584). Frequency of the heterozygous mutant Asp299Gly (AG) and Thr399Ile (CT) genotypes were significantly higher in the severe group compared to the non-severe $(42.7 \%$ and $28.0 \%$ vs $22.0 \%$ and $8.0 \%$, respectively), both of which were associated with a significant positive risk of severe COVID-19 (Asp299Gly (AG) genotype: OR 2.63; 95\% CI 1.59-4.36; $\mathrm{P}<0.001$ and Thr399Ile (CT) genotype: OR 4.47; 95\% CI 2.24-8.90; $\mathrm{P}<0.001)$.

The minor 299Gly (G) and 399Ile (T) alleles were associated with a significant positive risk of severe COVID-19 (OR 3.14; 95\% CI 2.02-4.88; P < 0.001 and OR 2.75; 95\% CI 1.66-4.57; P < 0.001, respectively), their frequency in the severe group were $71.8 \%$ (84/150) and $70.7 \%$ (58/150), respectively.

Furthermore, haplotype analysis was used to examine the additive effect of both SNPs. The frequency of the Asp299-
Thr399 (A-C) haplotype was $57.1 \%$ in the non-severe group and $42.9 \%$ in the severe group; they were associated with a significant negative risk of severe COVID-19 (OR 0.32; 95\% CI $0.21-0.47 ; \mathrm{P}<0.001)$. We found significant positive associations between- Asp299-Ile399 (A-T), Gly299-Thr399 (G-C) and Gly299-Ile399 (G-T) haplotypes and the risk of severe COVID-19 with a higher frequency in the severe group compared to the non-severe cohort (Asp299-Ile399 (A-T): 65.0\% vs 35.0\%; OR: 1.93; 95\% CI: 0.99-3.79; $\mathrm{P}=0.049)$, (Gly299-Thr399 (G-C): 69.3\% vs 30.7\%; OR: 2.52; 95\% CI: 1.50-4.24; $\mathrm{P}<0.001$ ) and (Gly299-Ile399 (G-T): 76.2\% vs 23.8\%; OR: 3.46; 95\% CI: 1.67-7.17; P <0.001), respectively.

\section{TLR-4 (Asp299Gly and Thr399lle) Genotypes and Levels of IL-6}

Regarding IL-6 levels, we found significant differences between TLR-4 Asp299Gly and Thr399Ile genotypes. The lowest IL-6 levels were associated with the wild Asp299Asp (AA) and Thr399Thr (CC) genotypes (31 pg/ $\mathrm{mL}(17-46)$ and $47.5 \mathrm{pg} / \mathrm{mL}$ (25-78), respectively) and significantly increased with the presence of the mutant 299Gly (G) and 399Ile (T) alleles to reach the highest levels in the Gly299Gly (GG) and the Ile399Ile (TT) genotypes (170 pg/mL (145-208.25) and $112 \mathrm{pg} / \mathrm{mL}$ (24-284.75), respectively) (Figure 3). 
Table 2 Baseline Characteristics of COVID-19 Patients Included (Non-Severe vs Severe)

\begin{tabular}{|c|c|c|c|c|}
\hline \multicolumn{2}{|l|}{ Variable } & \multirow{2}{*}{$\begin{array}{c}\text { Non- Severe } \\
(n=\mid 50)\end{array}$} & \multirow{2}{*}{$\begin{array}{l}\text { Severe } \\
(n=150)\end{array}$} & \multirow[t]{2}{*}{$\mathrm{p}$ - value } \\
\hline & & & & \\
\hline Age (years) & Median (IQR) & $42(30-58)$ & $55(40-67)$ & $<0.001$ \\
\hline \multirow[t]{2}{*}{ Sex n, (\%) } & Male & 55 (36.7\%) & $86(57.3 \%)$ & 0.288 \\
\hline & Female & 95 (63.3\%) & 64 (42.7\%) & \\
\hline \multirow[t]{5}{*}{ Comorbidities n, (\%) } & DM & $60(40.0 \%)$ & 79 (52.7\%) & 0.028 \\
\hline & HTN & $42(28.0 \%)$ & 78 (52.0\%) & $<0.001$ \\
\hline & IHD & II (7.3\%) & $34(22.7 \%)$ & 0.064 \\
\hline & CLD & 38 (25.3\%) & $22(14.7 \%)$ & 0.005 \\
\hline & CKD & 4 (2.7\%) & II (7.3\%) & $<0.001$ \\
\hline \multirow[t]{10}{*}{ Symptoms n, (\%) } & Cough & II (74.7\%) & 106 (70.7\%) & 0.437 \\
\hline & Diarrhea & $12(8.0 \%)$ & $22(14.7 \%)$ & 0.069 \\
\hline & Dyspnea & $104(69.3 \%)$ & 112 (74.7\%) & 0.304 \\
\hline & Fever & $100(66.7 \%)$ & $100(66.7 \%)$ & 1.000 \\
\hline & Fatigue & $128(85.3 \%)$ & 138 (92.0\%) & 0.069 \\
\hline & Arthralgia & 103 (68.7\%) & $120(80.0 \%)$ & 0.025 \\
\hline & Myalgia & $108(72.0 \%)$ & 116 (77.3\%) & 0.288 \\
\hline & Rhinitis & $18(12.0 \%)$ & $6(4.0 \%)$ & 0.011 \\
\hline & Loss of taste & 14 (9.3\%) & 10 (6.7\%) & 0.395 \\
\hline & Sore throat & $18(12.0 \%)$ & $26(17.3 \%)$ & 0.192 \\
\hline CT-SS & Median (IQR) & $5(0-15)$ & $20(|8-2|)$ & $<0.001$ \\
\hline CORADS & Median (IQR) & $3(1-5)$ & $5(5-6)$ & $<0.001$ \\
\hline IL-6 (pg/mL) & Median (IQR) & $17(11-23.5)$ & $54(30-88)$ & $<0.001$ \\
\hline \multirow[t]{2}{*}{ ICU admission n, (\%) } & Positive & 44 (29.3\%) & 49 (32.7\%) & 0.533 \\
\hline & Negative & $106(70.7 \%)$ & 101 (67.3\%) & \\
\hline Hospital stay (days) & Median (IQR) & $8(5-14)$ & $19(14-22)$ & $<0.001$ \\
\hline \multirow[t]{2}{*}{ Fate } & Discharged & 140 (93.3\%) & 112 (74.7\%) & $<0.001$ \\
\hline & Died & $10(6.7 \%)$ & 38 (25.3\%) & \\
\hline
\end{tabular}

Note: Bold values denote statistical significance at the $P<0.05$ level.

Abbreviations: CO-RADS, COVID-I 9 Reporting and Data System; CT-SS, Chest Computed Tomography Severity Scoring; ICU, Intensive care unit; IL-6, Interleukin-6.

\section{Discussion}

Data on immunological modulation, signaling pathways, and proinflammatory cytokines in SARS-CoV-2 infection can be used as a relevant platform for future pharmacological and vaccine studies. ${ }^{16}$ In the present study, which included 300 Egyptian COVID-19 patients, we found that severe COVID-19 was associated with TLR-4 (Asp299Gly and Thr399Ile) SNPs. The minor 299Gly (G) and 399Ile (T) alleles have been highly linked to severe COVID-19 and elevated IL-6 levels. Moreover, haplotype analysis showed that the co-segregation of both mutations was associated with a significantly a high risk for severe disease.
The TLR-4 gene is made up of four exons located on chromosome 9q32-33. TLR-4 protein is polymorphic, containing 12 single amino acid variations that occur infrequently. Arbor and colleagues described two polymorphic SNPs: +896A/G substitution, which replaces a conserved aspartic acid residue with glycine at amino acid (aa) $299+1196 \mathrm{C} / \mathrm{T}$ substitution, which replaces a threonine with isoleucine at (aa) 399. ${ }^{17}$ Both SNPs have been linked to reduced sensitivity to inhaled endotoxin. Furthermore, transfected cells with the minor allele of these SNPs had a decreased sensitivity to LPS and significantly lower production of the TLR-4 protein on the surface of epithelial cells in a cell culture 
Table 3 Frequency of TLR-4 Asp299Gly and Thr399lle SNPs (Genotypes, Alleles, and Haplotypes) and Their Association with the Risk of Severe COVID-19

\begin{tabular}{|c|c|c|c|c|c|c|c|}
\hline \multicolumn{2}{|l|}{ TLR-4 Polymorphism } & \multirow{2}{*}{$\begin{array}{c}\text { Non- } \\
\text { Severe }\end{array}$} & \multirow{2}{*}{$\begin{array}{l}\text { Severe } \\
(n=\mid 50)\end{array}$} & \multirow[t]{2}{*}{ P-value } & \multicolumn{2}{|c|}{ Severe COVID-19 Risk } & \multirow[t]{2}{*}{ P-value } \\
\hline & & & & & Odds Ratio & $95 \% \mathrm{Cl}$ & \\
\hline \multirow[t]{6}{*}{ rs4986790 genotypes } & \multirow[t]{2}{*}{ Asp299Asp (AA) } & 117 & 76 & \multirow{6}{*}{$<0.001$} & \multirow[t]{2}{*}{0.28} & \multirow[t]{2}{*}{$(0.17-0.47)$} & \multirow[t]{2}{*}{$<0.001$} \\
\hline & & (78.0\%) & $(50.7 \%)$ & & & & \\
\hline & \multirow[t]{2}{*}{ Asp299Gly (AG) } & 33 & 64 & & \multirow[t]{2}{*}{2.63} & \multirow[t]{2}{*}{$(1.59-4.36)$} & \multirow[t]{2}{*}{$<0.001$} \\
\hline & & (22.0\%) & (42.7\%) & & & & \\
\hline & \multirow[t]{2}{*}{ Gly299Gly (GG) } & 0.0 & 10 & & \multirow{2}{*}{\multicolumn{3}{|c|}{ NC }} \\
\hline & & $(0.0 \%)$ & $(6.7 \%)$ & & & & \\
\hline \multirow[t]{6}{*}{ rs498679I I genotypes } & \multirow[t]{2}{*}{ Thr399Thr (CC) } & 132 & 100 & \multirow{6}{*}{$<0.001$} & \multirow[t]{2}{*}{0.27} & \multirow[t]{2}{*}{$(0.15-0.49)$} & \multirow[t]{2}{*}{$<0.001$} \\
\hline & & (88.0\%) & $(66.7 \%)$ & & & & \\
\hline & \multirow[t]{2}{*}{ Thr399lle (CT) } & 12 & 42 & & \multirow[t]{2}{*}{4.47} & \multirow[t]{2}{*}{$(2.24-8.90)$} & \multirow[t]{2}{*}{$<0.001$} \\
\hline & & $(8.0 \%)$ & $(28.0 \%)$ & & & & \\
\hline & \multirow[t]{2}{*}{ Ile399Ile (TT) } & 6 & 8 & & \multirow[t]{2}{*}{0.73} & $(0.25-2.18)$ & 0.584 \\
\hline & & $(4.0 \%)$ & $(5.3 \%)$ & & & & \\
\hline rs4986790 alleles & Asp Allele (A) & 267 & 216 & & 0.31 & $(0.20-0.49)$ & $<0.001$ \\
\hline & & (55.3\%) & $(44.7 \%)$ & $<0.001$ & & & \\
\hline & Gly Allele (G) & 33 & 84 & & 3.14 & $(2.02-4.88)$ & $<0.001$ \\
\hline & & $(28.2 \%)$ & (71.8\%) & & & & \\
\hline rs498679I alleles & Thr Allele (C) & 276 & 242 & & 0.36 & $(0.21-0.60)$ & $<0.001$ \\
\hline & & (53.3\%) & $(46.7 \%)$ & $<0001$ & & & \\
\hline & Ile Allele (T) & 24 & 58 & & 2.75 & $(1.66-4.57)$ & $<0.001$ \\
\hline & & $(29.3 \%)$ & $(70.7 \%)$ & & & & \\
\hline Haplotype & A-C (Asp299- & 253 & 190 & & 0.32 & $(0.21-0.47)$ & $<0.001$ \\
\hline & Thr399) & (57.1\%) & $(42.9 \%)$ & & & & \\
\hline & A-T (Asp299-Ile399) & 14 & 26 & & 1.93 & $(0.99-3.79)$ & 0.049 \\
\hline & & (35.0\%) & $(65.0 \%)$ & & & & \\
\hline & G-C (Gly299- & 23 & 52 & & 2.52 & $(1.50-4.24)$ & $<0.001$ \\
\hline & Thr399) & (30.7\%) & (69.3\%) & & & & \\
\hline & G-T (Gly299-Ile399) & 10 & 32 & & 3.46 & $(1.67-7.17)$ & $<0.001$ \\
\hline & & $(23.8 \%)$ & (76.2\%) & & & & \\
\hline
\end{tabular}

Note: Bold values denote statistical significance at the $P<0.05$ level.

model. ${ }^{18}$ The generation of cytokines and inflammatory mediators like fibrinogen is also affected by these SNPs. ${ }^{19}$
A multitude of studies have investigated the association between these SNPs and different diseases. Although it seems that the minor alleles of TLR-41196C $>\mathrm{T}$ and 
A

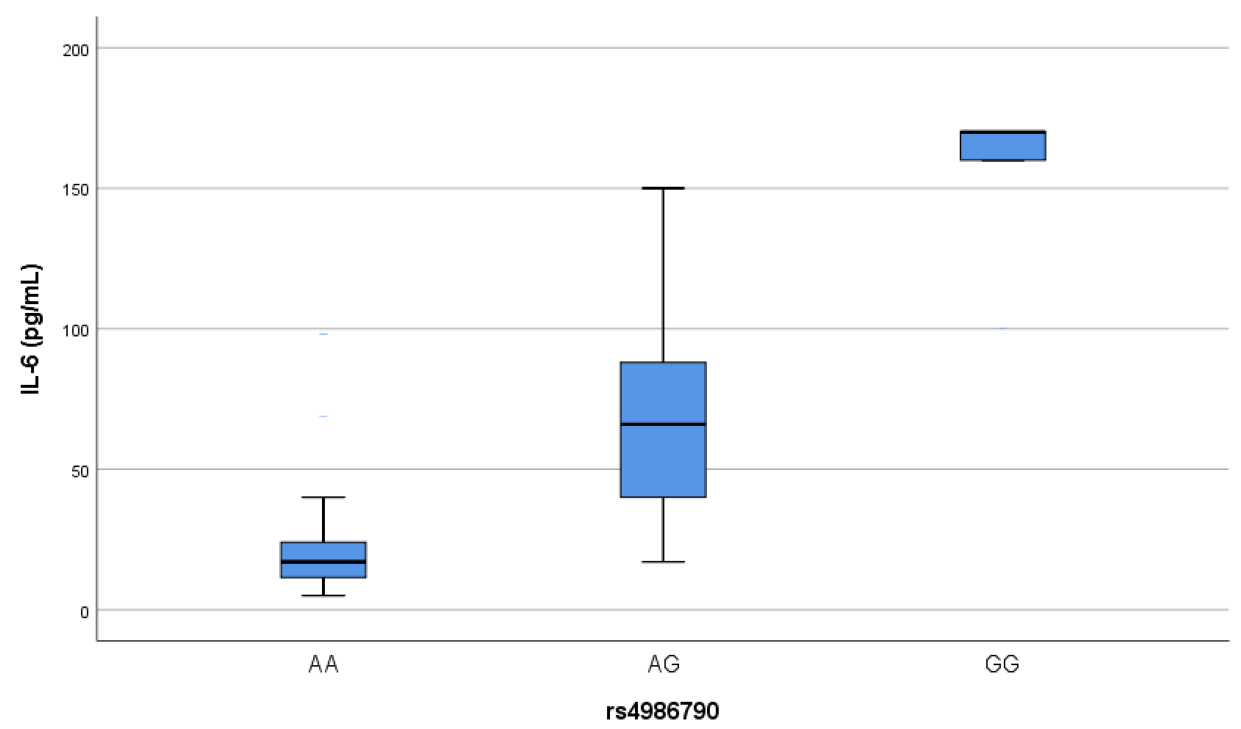

B

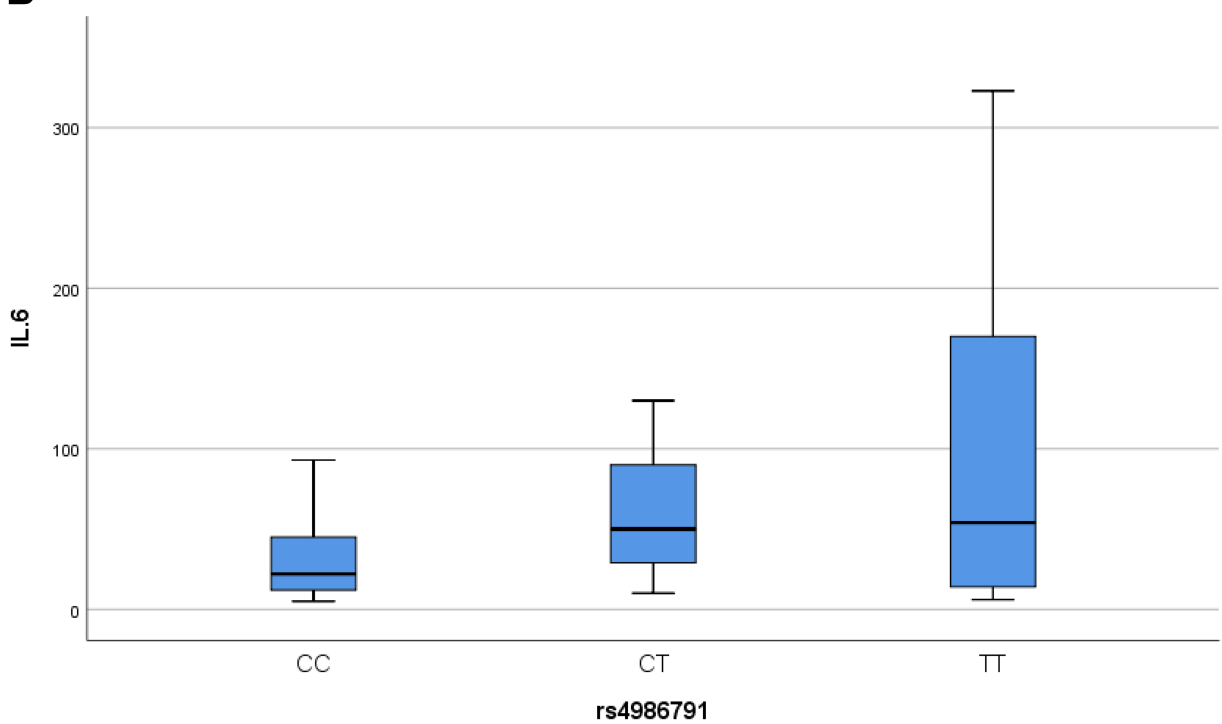

Figure 3 Box plot representing the range, median, and quartiles of IL- 6 levels in $\mathrm{pg} / \mathrm{mL}$ according to the different TLR-4 genotypes (tested by Kruskal-Wallis test) (A) rs4986790: Asp299Asp (AA):3I (17-46); Asp299Gly (AG):80 (60.25-96.75); Gly299Gly (GG): I70 (I45-208.25); P < 0.00I (B) rs498679I: Thr399Thr (CC): 47.5 (25-78); Thr399lle (CT): 76 (40-100); lle399lle (TT): II2 (24-284.75); P=0.013.

896A $>$ G SNPs predispose to several pathologies such as; gram-negative septic shock, ${ }^{20}$ premature birth, ${ }^{21}$ Crohn's disease, ${ }^{22}$ chronic osteomyelitis, ${ }^{23}$ urinary tract infection in children, ${ }^{24}$ respiratory syncytial virus (RSV) bronchiolitis in infants, ${ }^{25}$ Candida sepsis, ${ }^{26}$ chronic sarcoidosis, ${ }^{27}$ severe H-pylori infection and duodenal ulceration, ${ }^{28}$ some reports described a protective role for these SNPs against the development of diseases, such as; gastric lymphoma, ${ }^{29}$ neuropathy in diabetic patients, ${ }^{30}$ atherosclerosis with increased carotid artery compliance in young adults, ${ }^{19}$ acute allograft rejection, ${ }^{31}$ and Alzheimer's disease. ${ }^{32}$ In addition, minor alleles have not been directly linked to type 2 diabetes, but they may raise the risk of diabetic nephropathy through affecting levels of triglycerides and blood sugar. ${ }^{33}$

The SARS-CoV-2 genome encodes four proteins; spike $(\mathrm{S})$, membrane $(\mathrm{M})$, envelope (E), and nucleocapsid $(\mathrm{N})$. The virus invades host cells by interacting its $\mathrm{S}$ protein with the angiotensin-converting enzyme-2 (ACE-2) receptor on the host's cell membrane. It then enters the cell by endocytosis and uses its RNA and host machinery for replication. ${ }^{34}$ Because the ACE-2 is found in most vital organs and serves as a receptor for COVID-19, SARS-CoV-2 affects most organs, including the lungs, causing inflammation and fibrosis, which may affect vital functions, either temporarily or 
permanently, and sometimes result in death. ${ }^{35}$ Binding of viral S glycoprotein to ACE-2 on type II alveolar cells, which is responsible for the synthesis of pulmonary surfactant, results in cell lysis, exposing the extracellular binding sites of TLR-4 on lung epithelial cells. The exposed TLR-4 interacts with the viral $\mathrm{S}$ protein, facilitating viral entry to the neighboring cells, either directly or indirectly, through an increase in cell surface expression of ACE-2 by interferons. ${ }^{5}$ TLR-4-S protein interaction cause downstream signaling events towards the MYD88 dependent pro-inflammatory pathway, rather than the TRIF/TRAM dependent interferon pathway, with the production of innate pro-inflammatory cytokines (IL-1, IL-6, tumor necrosis factor- $\alpha$, and type 1 interferon $\alpha, \beta$ ) by macrophages, stimulating a robust innate immune response, and deflecting the adaptive immunity into a T-helper (Th)1/Th2 response in an attempt to clear the virus. ${ }^{5}$ In addition, an exaggerated Th2 cytokine response, especially IL-6, mediated by eosinophils, basophils, and mast cells, has been linked to immune response dysregulation in COVID-19, which further exacerbates the inflammatory reaction. ${ }^{36}$

Thus, by binding TLR-4, SARS-CoV-2 can trigger a rampant antiviral inflammatory state; if uncontrolled, especially in genetically predisposed individuals, it can ultimately end into a profound inflammatory reaction characterized by an increase in cytokines chemokines, and interferons, known as cytokine storm. ${ }^{37}$ The cytokine storm plays a crucial role in severe COVID-19 pathogenesis; it can lead to apoptosis of epithelial and endothelial cells, vascular leakage, and finally can end up into acute lung injury and ARDS, with fatal outcomes. ${ }^{38}$ Interestingly, in murine models of ARDS, including SARS-CoV-2, genetic inactivation of the TLR-4 gene was associated with the reduction in ARDS development. ${ }^{8}$ Furthermore, myocarditis, thrombosis, and multi-organ failure in severe COVID-19 cases have been linked to TLR-4-SARSCoV-2 interaction, with aberrant signaling in genetically predisposed patients, resulting in a hyper-inflammatory state. ${ }^{8}$

Finally, considering the well-established role of TLR-4 in the immunological responses to SARS-CoV-2, mutations in the TLR-4 gene may explain, at least in part, the broad spectrum of COVID-19 manifestations, as well as the unexplained progression of the disease in some patients. In addition, since TLR-4 antagonists have previously been trialed in sepsis and other antiviral contexts, ${ }^{5}$ TLR-4 appears to be a promising therapeutic target in genetically predisposed COVID-19 patients. Also, as several vaccines targeting SARS-CoV-2, S glycoprotein have been developed, the SNP within the TLR-4 gene can affect the TLR4-S protein interaction, and thus constituting a significant determinant of immune responses COVID-19 vaccines. Testing for SNP may help identify suitable immunization strategies for those individuals with incomplete responses to a particular vaccine strategy due to their genetic background. ${ }^{39}$

This study has limitations. First, the disproportionate sample size between the different genotypes and alleles hindered us from comparing their various clinical, laboratory, and radiological characteristics. Second, many coexisting non-genetic risk factors for COVID-19 severity were present in our patients and could have affected our results. Third, our study was conducted in a single hospital setting, offering a small representative population. Fourth, we measured only IL-6 as an indicator of the cytokine storm. More comprehensive studies on the correlation of TLR-4 SNPs with other inflammatory cytokines and the intracellular pathways are still required to understand better the role of TLR-4 gene mutations in COVID-19 pathogenesis.

\section{Conclusions}

Our study found that the TLR-4 SNPs (Asp299Gly) and (Thr399Ile) were associated with COVID-19 severity, cytokine storm, and mortality. Testing for TLR-4 SNPs may be helpful for early prediction of the course of the disease and early identification of patients who may benefit from the introduction of TLR-4 antagonists in the treatment regimen.

\section{Abbreviations}

ACE-2, angiotensin-converting enzyme-2; ARDS, adult respiratory distress syndrome; CO-RADS, COVID-19 Reporting and Data System; COVID-19, Corona virus disease 2019; CT, computed tomography; CT-SS, Chest Computed Tomography Severity Scoring; DAMPs, Damage-associated molecular patterns; EDTA, ethylenediaminetetraacetic acid; ELISA, enzyme-linked immunosorbent assay.; ICU, intensive care unit; LPS, lipopolysaccharide; PAMPs, pathogen-associated molecular patterns; PCR-RFLP, polymerase-chain reactionrestriction fragment length polymorphism; PRR, pattern recognition receptor; RT-PCR, real-time reverse transcription-polymerase-chain reaction; SARS-CoV-2, severe acute respiratory syndrome coronavirus-2; SNPs, single nucleotide polymorphisms; Th, T-helper; TLR-4, toll-like receptor 4; WHO, World Health Organization (WHO).

\section{Data Sharing Statement}

All the data needed to support the findings will be provided upon request. 


\section{Funding}

The authors did not receive any financial support to research, author and/or publish this article.

\section{Disclosure}

The authors declare no conflicts of interest for this work and that there are no potential conflicts of interest with respect to the research, authorship or publication of this article.

\section{References}

1. Cascella M, Rajnik M, Aleem A, Dulebohn SC, Di Napoli R. Features, evaluation, and treatment of coronavirus (COVID-19). In: StatPearls [Internet]. Treasure Island (FL): StatPearls Publishing; January, 2021. PMID: 32150360.

2. Cron RQ, Caricchio R, Chatham WW. Calming the cytokine storm in COVID-19. Nat Med. 2021;27(10):1674-1675. PMID: 34480126. doi:10.1038/s41591-021-01500-9

3. Tan L, Wang Q, Zhang D, et al. Lymphopenia predicts disease severity of COVID-19: a descriptive and predictive study. Signal Transduct Target Ther. 2020;5(1):33. PMID: 32296069; PMCID: PMC7100419. doi:10.1038/s41392-020-0148-4

4. Fouad SH, Allam MF, Ibrahim S, et al. ICU admission of COVID-19 patients: identification of risk factors. Egypt $J$ Anaesth. 2021;37 (1):202-207. doi:10.1080/11101849.2021.1919433

5. Aboudounya MM, Heads RJ. COVID-19 and Toll-Like Receptor 4 (TLR4): SARS-CoV-2 may bind and activate TLR4 to increase ACE2 expression, facilitating entry and causing hyperinflammation. Mediators Inflamm. 2021;2021:8874339. PMID: 33505220; PMCID: PMC7811571. doi:10.1155/2021/8874339

6. Satoh T, Akira S. Toll-like receptor signaling and its inducible proteins. Microbiol Spectr. 2016;4(6). PMID: 28084212. doi:10.1128/microbiolspec.MCHD-0040-2016

7. Kate Gadanec L, Qaradakhi T, Renee McSweeney K, Ashiana Ali B, Zulli A, Apostolopoulos V. Dual targeting of Toll-like receptor 4 and angiotensin-converting enzyme 2: a proposed approach to SARS-CoV-2 treatment. Future Microbiol. 2021;16:205-209. PMID: 33569984; PMCID: PMC7885526. doi:10.2217/fmb-20210018

8. Onofrio L, Caraglia M, Facchini G, Margherita V, Placido S, Buonerba C. Toll-like receptors and COVID-19: a two-faced story with an exciting ending. Future Sci OA. 2020;6(8):FSO605. PMID: 32974046; PMCID: PMC7434222. doi:10.2144/fsoa-2020-0091

9. Conte C. Possible link between SARS-CoV-2 infection and Parkinson's disease: the role of toll-like receptor 4. Int $\mathrm{J} \mathrm{Mol} \mathrm{Sci}$. 2021;22(13):7135. PMID: 34281186; PMCID: PMC8269350. doi:10.3390/ijms22137135

10. World Health Organization. Coronavirus disease (COVID-19) Weekly Epidemiological Update and Weekly Operational Update. Available from: https://www.who.int/emergencies/diseases/novel-cor onavirus-2019/situation-reports. Accessed November 22, 2021.

11. Prokop M, Van Everdingen W, Van Rees Vellinga T, et al. CO-RADS : a categorical CT assessment scheme for patients suspected of having COVID-19 definition and evaluation. Radiology. 2020;296(2):E97E104. PMID: 32339082; PMCID: PMC7233402. doi:10.1148/ radiol.2020201473

12. Francone M, Iafrate F, Masci GM, et al. Chest CT score in COVID-19 patients: correlation with disease severity and short-term prognosis. Eur Radiol. 2020;30(12):6808-6817. PMID: 32623505; PMCID: PMC7334627. doi:10.1007/s00330-020-07033-y
13. Pan F, Ye T, Sun P, et al. Time course of lung changes at chest CT during recovery from coronavirus disease 2019 (COVID-19). Radiology. 2020;295(3):715-721. PMID: 32053470; PMCID: PMC7233367. doi:10.1148/radiol.2020200370

14. Senhaji N, Diakité B, Serbati N, Zaid Y, Badre W, Nadifi S. Toll-like receptor 4 Asp299Gly and Thr399Ile polymorphisms: new data and a meta-analysis. BMC Gastroenterol. 2014;14:206. PMID: 25492126; PMCID: PMC4279599. doi:10.1186/s12876-014-0206-X

15. Folwaczny M, Glas J, Török HP, Limbersky O, Folwaczny C. Tolllike receptor (TLR) 2 and 4 mutations in periodontal disease. Clin Exp Immunol. 2004;135(2):330-335. PMID: 14738464; PMCID: PMC1808953. doi:10.1111/j.1365-2249.2004.02383.x

16. Zolfaghari Emameh R, Nosrati H, Eftekhari M, Falak R, Khoshmirsafa M. Expansion of single cell transcriptomics data of SARS-CoV infection in human bronchial epithelial cells to COVID-19. Biol Proced Online. 2020;22:16. PMID: 32754004; PMCID: PMC7377208. doi:10.1186/s12575-020-00127-3

17. Trejo-de la $\mathrm{O} \mathrm{A}$, Hernández-Sancén $\mathrm{P}$, Maldonado-Bernal $\mathrm{C}$. Relevance of single-nucleotide polymorphisms in human TLR genes to infectious and inflammatory diseases and cancer. Genes Immun. 2014;15(4):199-209. PMID: 24622688. doi:10.1038/ gene. 2014.10

18. Arbour NC, Lorenz E, Schutte BC, et al. TLR4 mutations are associated with endotoxin hyporesponsiveness in humans. Nat Genet. 2000;25(2):187-191. PMID: 10835634. doi:10.1038/76048

19. Kiechl S, Lorenz E, Reindl M, et al. Toll-like receptor 4 polymorphisms and atherogenesis. $N$ Engl J Med. 2002;347(3):185-192. PMID: 12124407. doi:10.1056/NEJMoa012673

20. Barber RC, Aragaki CC, Rivera-Chavez FA, Purdue GF, Hunt JL, Horton JW. TLR4 and TNF-alpha polymorphisms are associated with an increased risk for severe sepsis following burn injury. $J \mathrm{Med}$ Genet. 2004;41(11):808-813. PMID: 15520404; PMCID: PMC1383768. doi:10.1136/jmg.2004.021600

21. Lorenz E, Hallman M, Marttila R, Haataja R, Schwartz DA. Association between the Asp299Gly polymorphisms in the Toll-like receptor 4 and premature births in the Finnish population. Pediatr Res. 2002;52(3):373-376. PMID: 12193670. doi:10.1203/00006450200209000-00011

22. Browning BL, Huebner C, Petermann I, et al. Has toll-like receptor 4 been prematurely dismissed as an inflammatory bowel disease gene? Association study combined with meta-analysis shows strong evidence for association. Am J Gastroenterol. 2007;102(11):2504-2512. PMID: 17850411. doi:10.1111/j.1572-0241.2007.01463.x

23. Montes AH, Asensi V, Alvarez V, et al. The Toll-like receptor 4 (Asp299Gly) polymorphism is a risk factor for Gram-negative and haematogenous osteomyelitis. Clin Exp Immunol. 2006;143 (3):404-413. PMID: 16487238; PMCID: PMC1809620. doi:10.1111/j.1365-2249.2005.03002.x

24. Karoly E, Fekete A, Banki NF, et al. Heat shock protein 72 (HSPA1B) gene polymorphism and Toll-like receptor (TLR) 4 mutation are associated with increased risk of urinary tract infection in children. Pediatr Res. 2007;61(3):371-374. Erratum in: Pediatr Res. 2007 Oct;62(4):482. PMID: 17314700. doi:10.1203/pdr.0b013 e318030d1f4

25. Tulic MK, Hurrelbrink RJ, Prêle CM, et al. TLR4 polymorphisms mediate impaired responses to respiratory syncytial virus and lipopolysaccharide. J Immunol. 2007;179(1):132-140. PMID: 17579031. doi:10.4049/jimmunol.179.1.132

26. Van der Graaf CA, Netea MG, Morré SA, et al. Toll-like receptor 4 Asp299Gly/Thr399Ile polymorphisms are a risk factor for Candida bloodstream infection. Eur Cytokine Netw. 2006;17(1):29-34. PMID: 16613760

27. Pabst S, Baumgarten G, Stremmel A, et al. Toll-like receptor (TLR) 4 polymorphisms are associated with a chronic course of sarcoidosis. Clin Exp Immunol. 2006;143(3):420-426. PMID: 16487240; PMCID: PMC1809614. doi:10.1111/j.1365-2249.2006.03008.x 
28. Trejo-de la O A, Torres J, Pérez-Rodríguez M, et al. TLR4 single-nucleotide polymorphisms alter mucosal cytokine and chemokine patterns in Mexican patients with Helicobacter pylori-associated gastroduodenal diseases. Clin Immunol. 2008;129(2):333-340. PMID: 18755634. doi:10.1016/j.clim.2008.07.009

29. Hellmig S, Fischbach W, Goebeler-Kolve ME, Fölsch UR, Hampe J, Schreiber S. Association study of a functional Toll-like receptor 4 polymorphism with susceptibility to gastric mucosa-associated lymphoid tissue lymphoma. Leuk Lymphoma. 2005;46(6):869-872. PMID: 16019531. doi:10.1080/1042819050086451

30. Rudofsky G Jr, Reismann P, Witte S, et al. Asp299Gly and Thr399Ile genotypes of the TLR4 gene are associated with a reduced prevalence of diabetic neuropathy in patients with type 2 diabetes. Diabetes Care. 2004;27(1):179-183. PMID: 14693986. doi:10.2337/diacare.27.1.179

31. Palmer SM, Burch LH, Mir S, et al. Donor polymorphisms in Toll-like receptor-4 influence the development of rejection after renal transplantation. Clin Transplant. 2006;20(1):30-36. PMID: 16556150. doi:10.1111/j.1399-0012.2005.00436.x

32. Minoretti P, Gazzaruso C, Vito CD, et al. Effect of the functional tolllike receptor 4 Asp299Gly polymorphism on susceptibility to lateonset Alzheimer's disease. Neurosci Lett. 2006;391(3):147-149. PMID: 16157451. doi:10.1016/j.neulet.2005.08.047

33. Khaghanzadeh N, Naderi N, Pournasrollah N, Farahbakhsh E, Kheirandish M, Samiei A. TLR4 polymorphisms (896A $>$ G and $1196 \mathrm{C}>\mathrm{T}$ ) affect the predisposition to diabetic nephropathy in type 2 diabetes mellitus. Diabetes Metab Syndr Obes. 2020;13:1015-1021. PMID: 32308451; PMCID: PMC7138628. doi:10.2147/DMSO.S238942
34. Malik YA. Properties of Coronavirus and SARS-CoV-2. Malays J Pathol. 2020;42(1):3-11. PMID: 32342926.

35. Zolfaghari Emameh R, Falak R, Bahreini E. Application of system biology to explore the association of neprilysin, angiotensin-converting enzyme 2 (ACE2), and carbonic anhydrase (CA) in pathogenesis of SARS-CoV-2. Biol Proced Online. 2020;22:11. PMID: 32572334; PMCID: PMC7302923. doi:10.1186/s12575-020-00124-6

36. Roncati L, Nasillo V, Lusenti B, Riva G. Signals of Th2 immune response from COVID-19 patients requiring intensive care. Ann Hematol. 2020;99(6):1419-1420. PMID: 32382776; PMCID: PMC7205481. doi:10.1007/s00277-020-04066-7

37. Brandão SCS, Ramos JOX, Dompieri LT, et al. Is Toll-like receptor 4 involved in the severity of COVID-19 pathology in patients with cardiometabolic comorbidities? Cytokine Growth Factor Rev. 2021;58:102-110. PMID: 32988728; PMCID: PMC7505161. doi:10.1016/j.cytogfr.2020.09.002

38. Tang Y, Liu J, Zhang D, Xu Z, Ji J, Wen C. Cytokine storm in COVID-19: the current evidence and treatment strategies. Front Immunol. 2020;11:1708. PMID: 32754163; PMCID: PMC7365923. doi:10.3389/fimmu.2020.01708

39. Pellegrino P, Falvella FS, Cheli S, Perrotta C, Clementi E, Radice S. The role of Toll-like receptor 4 polymorphisms in vaccine immune response. Pharmacogenomics J. 2016;16(1):96-101. PMID: 25823688. doi:10.1038/tpj.2015.21
Journal of Inflammation Research

\section{Publish your work in this journal}

The Journal of Inflammation Research is an international, peerreviewed open-access journal that welcomes laboratory and clinical findings on the molecular basis, cell biology and pharmacology of inflammation including original research, reviews, symposium reports, hypothesis formation and commentaries on: acute/chronic inflammation; mediators of inflammation; cellular processes; molecula mechanisms; pharmacology and novel anti-inflammatory drugs; clinical conditions involving inflammation. The manuscript management system is completely online and includes a very quick and fair peerreview system. Visit http://www.dovepress.com/testimonials.php to read real quotes from published authors. 